\title{
Visualization and evaluation of chemoembolization on 3D decellularized organ scaffold
}

Xu Gao, Zijian Chen, Zhengchang Chen, Xiaoya Liu, Yucheng Luo, Jingyu Xiao, Yanan Gao, Yutao Ma, Chuang Liu, Hwa Liang Leo, Hanry Yu, and Qiongyu Guo*

a

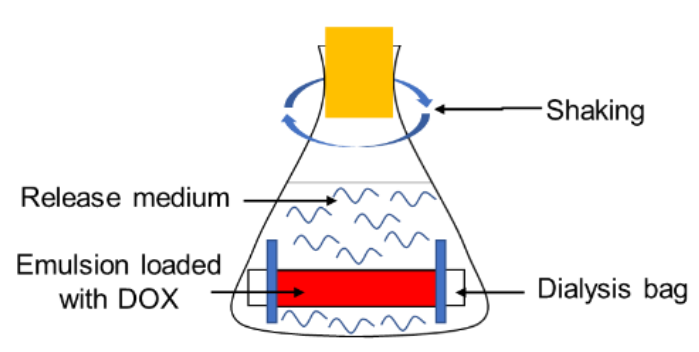

d

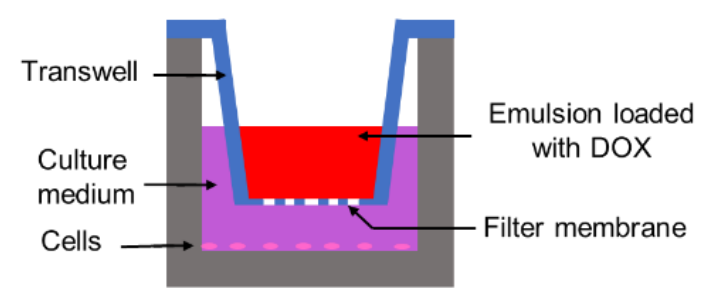

b

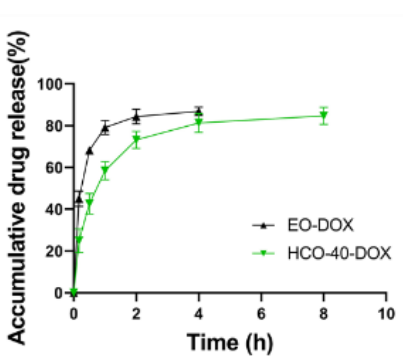

e

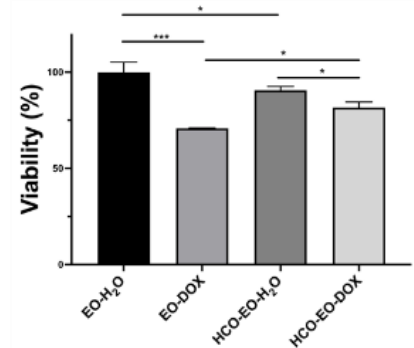

C

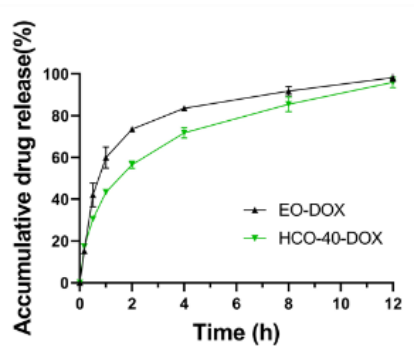

Fig. S1 Drug release profile and viability test of ethiodised oil-based emulsion. a-c. Drug releasing experimental scheme (a) and profiles (b: $37^{\circ} \mathrm{C}$; c: $20^{\circ} \mathrm{C}$ ) for EO-DOX and HCO-EO-DOX. d-e. Cell viability experimental scheme (d) and result (e) for EO-DOX and HCO-EO-DOX. ${ }^{*} p<0.05,{ }^{* * *} p<0.001$.

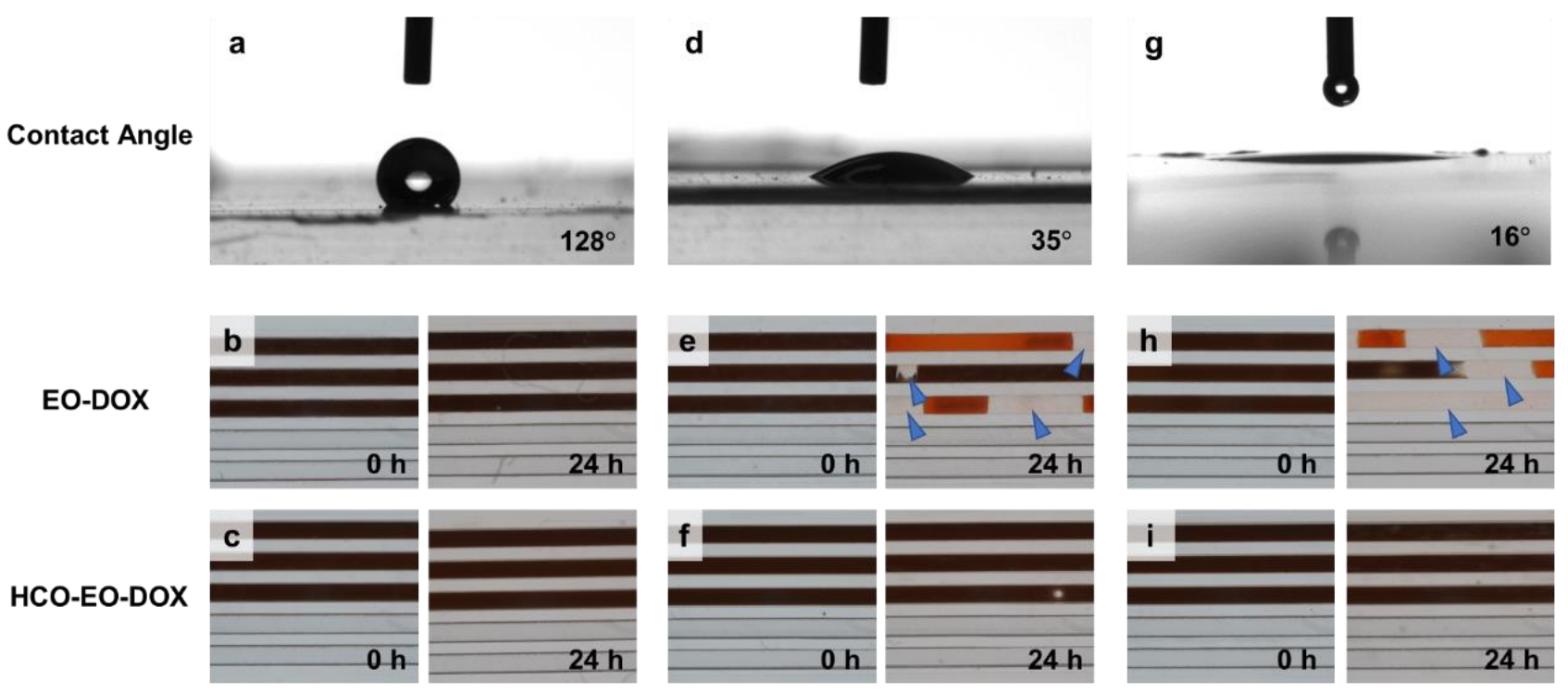

Fig. S2 Emulsion stability of EO-DOX and HCO-EO-DOX in microfluidic channels coated with trichloro (a-c), plasma treating for $2.5 \mathrm{~min}$ (d-f), and plasma treating for $10 \mathrm{~min}$ (g-i). 

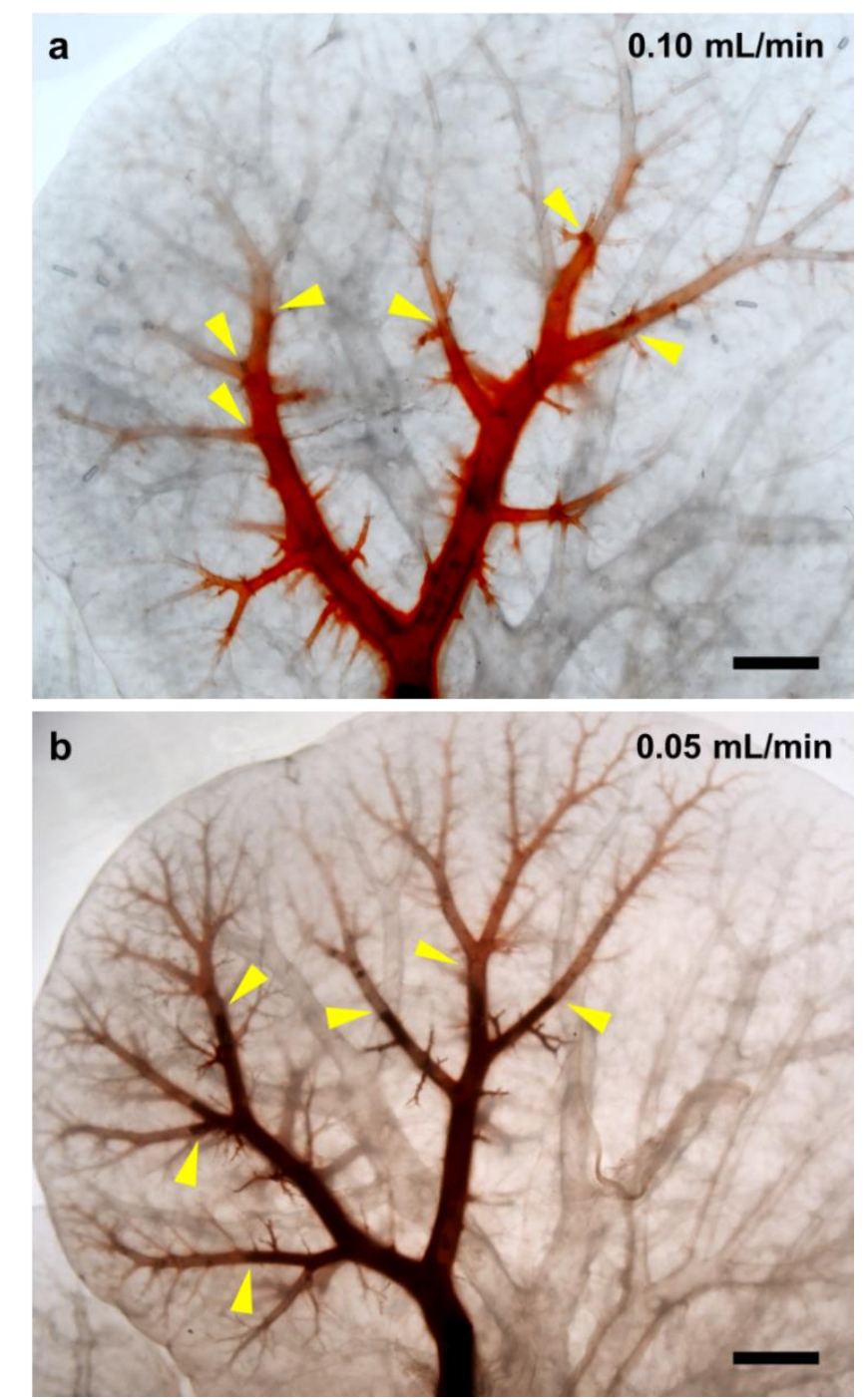

Fig. S3 Flow rate effect on embolization behavior of EO-DOX in DLM: $0.10 \mathrm{~mL} / \mathrm{min}$ (a) and $0.05 \mathrm{~mL} / \mathrm{min}$ (b).

Table S1 The parameters of the finite element models of liver and kidney

\begin{tabular}{|c|c|c|c|c|c|c|c|}
\hline Models & $\begin{array}{l}\text { \#Poly. } \\
\text { cells }\end{array}$ & $\begin{array}{l}\text { Aspect } \\
\text { Ratio }\end{array}$ & $\begin{array}{l}\text { Aspect } \\
\text { Ratioavg }\end{array}$ & Skewness & Skewnessavg & $\begin{array}{l}\text { Cell Size } \\
\left(\mu m^{3}\right)\end{array}$ & $\begin{array}{l}\text { Cell } \\
\text { Size }_{a v g} \\
\left(\mu m^{3}\right)\end{array}$ \\
\hline Liver & 188876 & $1.36-5.04$ & 1.85 & $0.00-0.45$ & 0.03 & 517.6-3219 & 2217 \\
\hline Kidney & 163481 & $1.35-5.06$ & 1.84 & $0.00-0.61$ & 0.03 & $417.2-3337$ & 2218 \\
\hline
\end{tabular}

